\title{
Transpiration and water uptake of Senecio medley-woodii and Aloe jucunda under changing environmental conditions: measurements with a potometric water-budget-meter
}

\author{
Flach, Barbara ; Egli, A ; Eller, B M
}

\begin{abstract}
Transpiration, water uptake by the roots and CO2 exchange of two leaf succulents, Senecio medleywoodii (Asteraceae) and Aloe jucunda (Asphodeliaceae), were monitored simultaneously and continuously with a gas exchange cuvette combined with an apparatus to quantify water uptake (= waterbudgetmeter). Measurements, which are primarily valid for plants with a sufficient water supply, were made with the same plant for up to 29 consecutive days. Ambient air temperature varied between 17 and $35^{\circ} \mathrm{C}$ with a constant dewpoint temperature of $13^{\circ} \mathrm{C}$ of the ambient air and a $12 \mathrm{~h}$ photoperiod at $400-500 \mu \mathrm{mol}$ $\mathrm{m}-2 \mathrm{~s}-1$ photon irradiance. The net water flux ( $\mathrm{Jw}($ net $)=$ water uptake-transpiration) and the water balance ( $\mathrm{Jw}($ net) integrated for a timespan) were calculated. Various tests were made to determine the accuracy of the measurements made with this rather complex equipment. In most cases the errors for transpiration and uptake rates were much lower than $8 \%$ determined under the conditions of drastically (about $10 \mathrm{~K}$ per $30 \mathrm{~min}$ ) increased or decreased ambient air temperatures. The experimental set-up proved to be a most valuable tool to determine and analyse interactions between transpiration and water uptake, changes in plant water status and the buffering of negative Jwnet). Increasing the temperature of ambient air resulted, for both species investigated, in a quick and considerably enhanced transpiration, but there was only a minor impact on water uptake. Water loss exceeding uptake was buffered by internal water reserves which were refilled within about $1 \mathrm{~d}$ after the plant was relieved of heat and drought stress caused by a period of high ambient air temperatures and high water vapour saturation deficits of the air. Repeated simulation of such stress periods showed that the absolute values of transpiration and the water uptake for $24 \mathrm{~h}$ can vary, but the diurnal course of the values showed the same pattern if the environmental conditions were identical. Such standardized diurnal transpiration and water uptake curves could be very useful for the validation of mathematical models used to describe plant water relations
\end{abstract}

DOI: https://doi.org/10.1093/jxb/46.10.1615

Posted at the Zurich Open Repository and Archive, University of Zurich

ZORA URL: https://doi.org/10.5167/uzh-154167

Journal Article

Published Version

Originally published at:

Flach, Barbara; Egli, A; Eller, B M (1995). Transpiration and water uptake of Senecio medley-woodii and Aloe jucunda under changing environmental conditions: measurements with a potometric waterbudget-meter. Journal of Experimental Botany, 46(10):1615-1624.

DOI: https://doi.org/10.1093/jxb/46.10.1615 


\title{
Transpiration and water uptake of Senecio medley-woodii and Aloe jucunda under changing environmental conditions: measurements with a potometric water-budget-meter
}

\author{
Barbara M.-T. Flach, Benno M. Eller ${ }^{1}$ and Armin Egli \\ Institut für Pflanzenbiologie, Universität Zürich, Zollikerstrasse 107, CH-8008 Zürich, Switzerland
}

Received 21 December 1994; Accepted 20 June 1995

\begin{abstract}
Transpiration, water uptake by the roots and $\mathrm{CO}_{2}$ exchange of two leaf succulents, Senecio medleywoodii (Asteraceae) and Aloe jucunda (Asphodeliaceae), were monitored simultaneously and continuously with a gas exchange cuvette combined with an apparatus to quantify water uptake (= waterbudget-meter). Measurements, which are primarily valid for plants with a sufficient water supply, were made with the same plant for up to 29 consecutive days. Ambient air temperature varied between 17 and $35^{\circ} \mathrm{C}$ with a constant dewpoint temperature of $13^{\circ} \mathrm{C}$ of the ambient air and a $12 \mathrm{~h}$ photoperiod at 400-500 $\mu \mathrm{mol} \mathrm{m}^{-2} \mathrm{~s}^{-1}$ photon irradiance. The net water flux $\left(J_{w}(n e t)=\right.$ water uptake - transpiration) and the water balance ( $J_{w}(n e t)$ integrated for a timespan) were calculated. Various tests were made to determine the accuracy of the measurements made with this rather complex equipment. In most cases the errors for transpiration and uptake rates were much lower than $8 \%$ determined under the conditions of drastically (about $10 \mathrm{~K}$ per $30 \mathrm{~min}$ ) increased or decreased ambient air temperatures. The experimental set-up proved to be a most valuable tool to determine and analyse interactions between transpiration and water uptake, changes in plant water status and the buffering of negative $J_{w}$ (net).

Increasing the temperature of ambient air resulted, for both species investigated, in a quick and considerably enhanced transpiration, but there was only a minor impact on water uptake. Water loss exceeding
\end{abstract}

uptake was buffered by internal water reserves which were refilled within about $1 \mathrm{~d}$ after the plant was relieved of heat and drought stress caused by a period of high ambient air temperatures and high water vapour saturation deficits of the air. Repeated simulation of such stress periods showed that the absolute values of transpiration and the water uptake for $24 \mathrm{~h}$ can vary, but the diurnal course of the values showed the same pattern if the environmental conditions were identical. Such standardized diumal transpiration and water uptake curves could be very useful for the validation of mathematical models used to describe plant water relations.

Key words: Plant water relations, water budget, drought stress, transpiration, water uptake.

\section{Introduction}

Water in a plant is frequently quantified by the vague though nevertheless useful term 'plant water status' (Passioura, 1982). Throughout this text this term is used to describe relative water content qualitatively. The plant exchanges water with its environment by two kinds of water fluxes, firstly water gains $\left(J_{w g}\right)$ through uptake by the roots and other surfaces, and secondly water loss $\left(J_{w 1}\right)$, predominantly by transpiration and the resulting $J_{w}(n e t)$ represents the flux of water that increases or decreases the plant's water status.

$$
J_{w}(n e t)=J_{w g}-J_{w l} .
$$

Usually, higher plants are rooted in a substrate and water

\footnotetext{
1 To whom correspondence should be addressed. Fax: +4113854204. Abbreviations: $\mathrm{CAM}=$ crassulacean acid metabolism, $\mathrm{WBM}=$ water-budget-meter .
} 
uptake from this substrate is supposed to compensate water loss by transpiration. However, in reality an equilibrium between uptake rates and transpiration rates hardly exists. For a given time period $t_{2}-t_{t}$, the input and output of water to a plant constitutes the water balance $\Delta M_{w}$

$$
\Delta M_{w}=\int_{t_{1}}^{t_{2}} J_{w}(n e t)=\int_{t_{1}}^{t_{2}} J_{w g} d t-\int_{t_{1}}^{t_{2}} J_{w l} d t=\Delta M_{w g}+\Delta M_{w x}
$$

where $\Delta M_{w g}$ is the water consumed for growth and $\Delta M_{w s}$ is the mass of water changing the plant's water reserves. For plants with an optimum water supply one can assume that the water content is very high and thus the amount of water stored not changed, for example, for a $24 \mathrm{~h}$ period. Therefore, one can assume that the value of $\Delta M_{w s}$ is negligible and, consequently, a positive $\Delta M_{w}$ persisting for several consecutive days indicates growth and $\Delta M_{w}$ then represents the amount of water consumed by growth. However, in certain circumstances growth can also occur (e.g. growth of leaves or flowering) solely on internal water reserves (Matyssek et al., 1991; von Willert et al., 1992).

One fraction of a plant's water guarantees the plant's structure and viability, for example, as the solvent of the cytoplasm, the other fraction is water that can buffer water loss during periods with negative $J_{w}($ net $)$. Plants with large storage volumes, such as trees (Milne, 1989) or succulents (von Willert et al., 1992), can tolerate considerable water loss and thus survive long drought periods. In contrast, plants with small water stores can not tolerate negative values of $J_{w}($ net $)$ for a longer time period since this would affect the plant's viability. However, in such a case the plant water potential varies instantly, concomitant with transpiration, mainly as a consequence of decreasing turgor pressure caused by the water loss. The lowered plant water potential enhances uptake if water is available from the substrate and the curve for water uptake follows that of transpiration (Brunner and Eller, 1975) and thus gain and loss are closely linked. The time shift between loss by transpiration and gain by uptake from the substrate depends on the amount of the internal water reserves of that plant, the hydraulic conductivities involved and the availability of water from the substrate. If a larger water store buffers diurnal water loss, then water uptake by the roots is to some extent unlinked from actual transpiration rates, i.e. transpiration peaks are not repeated in the pattern of diurnal water uptake or are shifted in time and smoothed (Whitehead and Jarvis, 1981; Ruess et al., 1988). Moreover, osmotically effective metabolic specializations like the crassulacean acid metabolism (CAM) also affect water uptake (Ruess and Eller, 1985; Lattge, 1987; Griffiths, 1988; Eller et al, 1993).

There are a variety of established methods to measure transpiration, from the simple conventional potometer to the sophisticated automatic controlled, air-conditioned gas exchange cuvette systems, but difficulties increase if one intends to quantify water uptake by the roots or to measure growth in a non-destructive way. Assuming that sap flow in the stem is equal to the water uptake by the roots then sap flow meters (Baker and Van Bavel, 1987) could be used to quantify uptake, but stem flow measurements are made preferably to determine in situ transpiration of complex or large herbaceous or woody plants. If the water storage capacity of plants is low, then stem flow quite accurately represents transpiration (Schulze et al., 1985; Baker and Van Bavel, 1987). However, in many cases the plant's morphology excludes these methods for geometrical reasons and values from sap flow measurements certainly do not represent true water uptake if one has to take into account water stored in the plant's roots or the stem.

Potometric systems with the plant's roots bathing in a hydroculture solution can quantify water uptake directly, but conventional potometers can not monitor transpiration and water uptake continuously. Ruess and Eller (1985) made a new approach combining a cuvette system, frequently used for investigations of $\mathrm{CO}_{2}$ gas exchange and transpiration with a system for a potometric determination of water uptake. A severe handicap for potometric determinations of transpiration and/or water uptake is the sensitivity of such systems to temperature changes. The equipment of Ruess and Eller (1985) and Eller et al. (1993) allowed only water budget determinations under constant environmental conditions. In the meantime the experimental set-up of Ruess and Eller (1985) was substantially improved and investigations with changing environmental conditions can be made.

The aims of this study were: firstly, to demonstrate that this equipment is now qualified for accurate investigations under changing ambient air temperatures not only of water loss of a plant by transpiration, but also of its concomitant water uptake and thus the water fluxes from and to a plant. Secondly, to what extent are the water reserves used to buffer short periods of negative $J_{w}(n e t)$ or is the water uptake also enhanced. Thirdly, it was to demonstrate that results can be reproduced and repeated during time periods of more than 4 weeks and can be used to analyse whether there are distinct differences between different types of leaf succulents in the use of the stored water reserves, transpiration and the plant's relative water content or not.

\section{Materials and methods}

\section{Plant material and environmental conditions}

Two leaf succulents, Senecio medley-woodii Hutchins. (Hilliard, 1977) and Aloe jucunda Reynolds (Reynolds, 1966) were used for the investigations. Both species perform the crassulacean 
acid metabolism (CAM) and are shrublets growing in arid habitats in southern Africa ( $S$. medley-woodii) or in Madagascar ( $A$. jucunda). Plants were propagated from specimens collected in their habitats and cultivated in growth cabinets at 'standard day' conditions (Fig. 1, S). The photoperiod was $12 \mathrm{~h}$ with a photon irradiance of about $400-500 \mu \mathrm{mol} \mathrm{m}^{-2} \mathrm{~s}^{-1}$ determined with a quantum sensor (Licor Ltd., Lincoln, USA). Irradiation conditions were not changed during the investigations. Automatic control of ambient air temperature and relative air humidity was by on-line computer control based on datafiles of environmental conditions recorded in southern Africa in habitats of other leaf succulents. Two characteristic days were chosen to investigate the plant's diurnal water fluxes, firstly a day with moderate air temperature (Fig. 1, S) subsequently refered to as 'standard day' (or S) and secondly a day with a higher air temperature (Fig. $1, \mathrm{H}=$ hot day). The transitions from lower to higher temperatures (Fig. 1, P) and vice versa (Fig. 1, M) were made in a very short time period to provoke distinct changes of the plant's water exchange with the environment and of the water exchanged with the plant's water store. Some data from investigations made at constant temperatures and dewpoint $\left(20 / 13^{\circ} \mathrm{C}\right.$ and $30 / 13^{\circ} \mathrm{C}$, ambient/dewpoint) are also presented in the results. Growth or changes in the mass of stored water $\left(=\Delta M_{w o s}\right)$ must result in leaf volume changes or other leaf dimensions. However, only in rare exceptions are non-destructive determinations of leaf volume changes feasible. For spatial reasons, one could not quantify in a non-destructive way such volume changes of growing leaves of a $S$. medleywoodii or $A$. jucunda plant enclosed in a gas exchange cuvette.

\section{The potometric water-budget-meter}

The experimental apparatus, termed a water-budget-meter (WBM) is shown in Fig. 2. In this potometric system $\mathrm{CO}_{2}$ gas exchange and transpiration were determined with a computer controlled cuvette system after Koch et al. (1968) as described by Eller et al. (1993). Transpiration $J_{w l}$ was calculated from air flow through the cuvette and the difference of the air humidities measured at the inlet and outlet of the cuvette. The plants were mounted into the gas exchange cuvette with their roots bathed in a water container fixed on a balance (PL 1200, Mettler, Greifensee, Switzerland) used to determine water uptake $J_{\text {ws }}$ (Fig. 2). Water uptake is $\Delta$ weight of that container. The hydroculture solution in that container was temperature controlled (constant, $15^{\circ} \mathrm{C}$ ) and its oxygen concentration adjusted to $7-8 \mathrm{~g} \mathrm{~m}^{-3}$ (near saturation). This value was continuously monitored by an $\mathrm{O}_{2}$-sensitive electrode and the concentration maintained by $\mathrm{O}_{2}$-diffusion via a tube of silicon rubber. If water uptake is assumed to be represented by changes in weight recorded by the balance then one has to avoid changes of buoyancy caused by increasing or decreasing ambient air temperature. For this, the gas exchange cuvette with the immobilized plant was connected with rigid steel rods of extremely low thermal expansion coefficient $\left(<1.7 \mu \mathrm{m} \mathrm{m}^{-1} \mathrm{~K}^{-1}\right)$ to the platform of the balance. The water uptake by the plant decreased the level of water in the container and, consequently, decreased buoyancy. The changes in buoyancy were determined for each plant and used to calculate the proper values for water uptake. These corrections were in the order of $20-30 \%$ of $\Delta$ weight. The plant growth cabinet generated vibrations which interfered with the weighing procedure. To minimize such errors the vibration sources were switched off during the weighing procedure. Every $2 \mathrm{~min}$ a set of data and calculated results were registered and from five sets mean values for $10 \mathrm{~min}$ were calculated for final results.
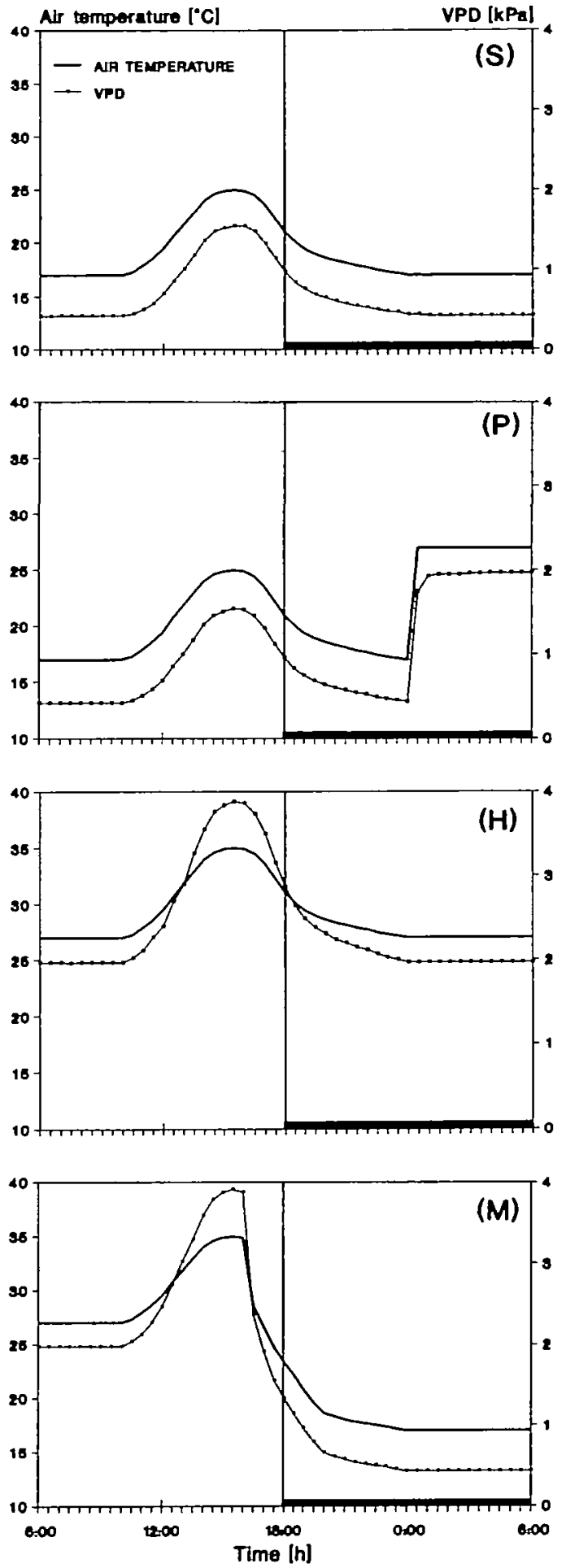

Fig. 1. Temperature and water vapour saturation deficit (VPD) of ambient air for the simulation of weather conditions. Photon irradiance $470 \pm 70 \mu \mathrm{mol} \mathrm{m} \mathrm{m}^{-2} \mathrm{~s}^{-1}$. Black bar indicates dark period. (S) Standard day, (P) transition from standard day to hot day, (H) hot day, (M) transition from hot day to standard day. In the subsequent figures the capital letters $S, P, H$, and $M$ were used to refer to these environmental conditions. 


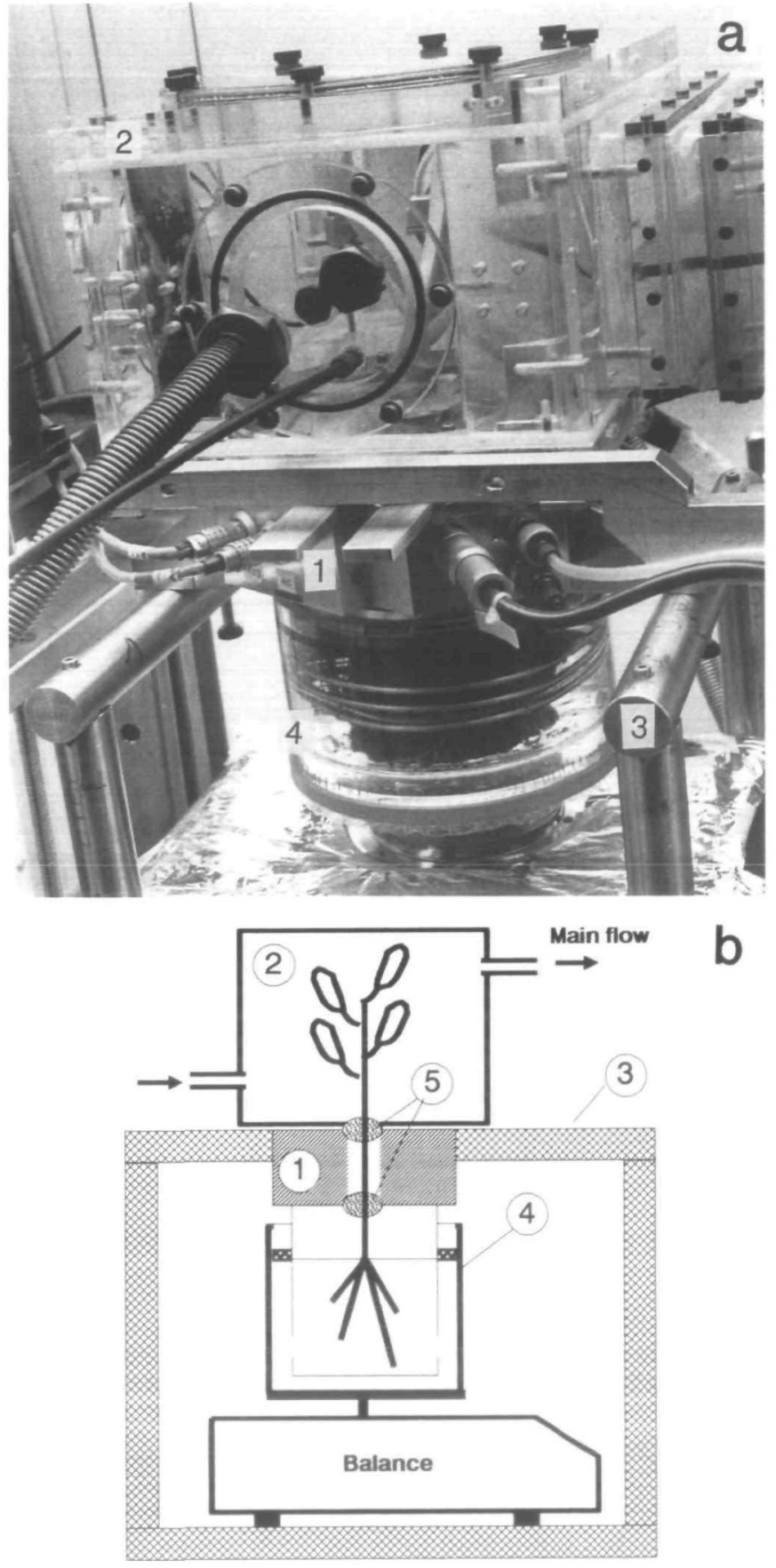

Fig. 2. The water-budget-meter (WBM) in operation (a) and its schematic drawing (b). 1: Control unit with attached inner container (this inner container prevents sedimentation of root debris and soil particles into the outer container (4) mounted on the balance). 2: Gas exchange cuvette for the determination of $\mathrm{CO}_{2}$ exchange and transpiration. 3: Steel cage connecting control unit with platform of the balance. 4: Outer container on the pan of the balance with oil seal preventing evaporation to ambient air. 5: Airtight seals fixing the plant to the control unit and the gas exchange cuvette. Wind and radiation shields are not shown.

\section{Accuracy of measurements}

The accuracy of transpiration and water uptake rates was estimated with tests as already outlined in Eller et al. (1993). For the temperature conditions (Fig. 1) of the experiments and if time periods of more than $1 \mathrm{~d}$ were considered, then the values for water uptake and transpiration showed an error span of less than $\pm 3 \%$. For shorter time periods $(6-24 \mathrm{~h})$ the span was larger but less than $\pm 6 \%$. The smallest significant $\Delta$ uptake rate for $30 \mathrm{~min}$ (as used for the graphic presentation of results) is $0.3 \mu \mathrm{mol} \mathrm{s}^{-1}$ which is less than $8 \%$ of an uptake rate of $4 \mu \mathrm{mol} \mathrm{s}^{-1}$ (Fig. 4).

Tests were made to ascertain that time shifts between the plant's transpiration and its uptake rates and the smoothing of peak values were not artifacts generated by the rather complex experimental set-up. For this a herbaceous plant with the $C_{3}$ pathway of photosynthesis, Pilea cadierei Gagnep. et A. Guill. was chosen. Because of its low water storage capacity one could expect that at the end of the light period the uptake rate would follow decreasing transpiration rate without a significant time lag. In all tests the transpiration and water uptake curves showed the same pattern and no distinct shift in time was observed (Fig. 3). Therefore one must conclude that observed time lags between uptake and transpiration depict the plant's performance and are not due to systematic errors generated by the equipment. The leaves of the Pilea cadierei were fully turgescent and thus one could assume an optimal plant water status. Leaf and root growth was observed which evidently caused the water uptake to exceed transpiration to a small extent (Fig. 3).

\section{Results and discussion}

Measurements of $\mathrm{CO}_{2}$ exchange, transpiration and water fluxes were made for 7 to 29 consecutive days without changing the plant under investigation. The plant's physiological performance was not affected by external interferences except the controlled changes of environmental parameters. Two plants of $S$. medley-woodii and three of $A$. jucunda were monitored in this investigation with rapidly changing ambient air temperatures. The individuals of each species showed similar results and so only the results of the plant with the longest time period

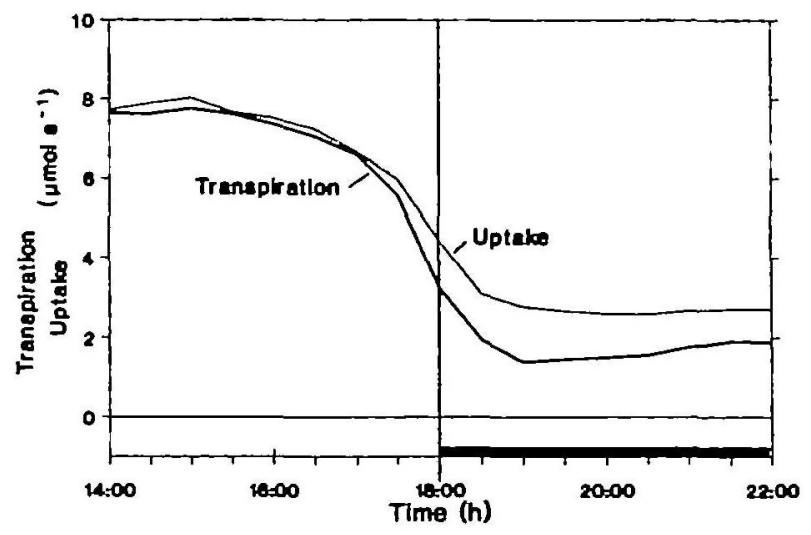

Fig. 3. Transpiration and water uptake of the herbaceous Pilea cadierei (non-succulent, $\mathrm{C}_{3}$ pathway of photosynthesis) during stomatal closure at the end of the light-period $(18.00 \mathrm{~h})$. Environmental conditions: Standard day (Fig. 1, S). 
of observations are presented below. Results with $S$. medley-woodii under constant environmental conditions were already published by Ruess and Eller (1985) and Eller et al. (1992).

One plant of $S$. medley-woodii was monitored continuously in the WBM for a time period as long as $29 \mathrm{~d}$. Its physiological performance was excellent and unchanged during the measurements. The plant showed continuous growth of roots and leaves. After acclimatization in the WBM this plant was subject to three cycles of hot day periods (hot day period $=$ combination $\mathrm{S}+\mathrm{P}+\mathrm{H}+\mathrm{M}+\mathrm{S}$, Fig. 1) to investigate the plant's reaction to short-term changes in temperature and at a generally higher daytime temperature. The temperature cycle was repeated three times to reveal changes from one cycle to the next. After the third cycle the climatic conditions were held for a whole week at hot day conditions to provoke high water loss during the light period (Fig. 1, H). Subsequently, a period of constant high air temperature $\left(30^{\circ} \mathrm{C}\right)$ was applied day and night to see the plant's reaction to high nocturnal air temperatures.

The plant's performance is summarized in Figs 4 and 5 , with diurnal variations of water fluxes and changes in water relations during the second hot day period presented in Fig. 4. The sudden rise of temperature at midnight of day $\mathrm{P}$ (Fig. 4) provoked an immediate drop in the $\mathrm{CO}_{2}$ dark fixation and increased transpiration, but the water uptake rate increased less. Uptake was maximal between $07.00 \mathrm{~h}$ and $08.00 \mathrm{~h}$ on the next morning whereas the maximal nocturnal transpiration was about $01.30 \mathrm{~h}$. The plant's reaction during the other two hot day periods was similar. Uptake started to increase with a short time lag (about $1.5 \mathrm{~h}$ at $16.00 \mathrm{~h}$ on day $\mathrm{M}$ ) after transpiration increased, but the peak values of transpiration and uptake were approximately $6 \mathrm{~h}$ apart. Comparing the magnitude of changes in uptake provoked by the increased transpiration, the result was contradictory. The $\Delta$ transpiration of $3.4 \mu \mathrm{mol} \mathrm{s}^{-1}$ in the dark period (Fig. 4, P) is followed by a $\Delta$ uptake of $1.4 \mu \mathrm{mol} \mathrm{s}^{-1}$ (about $40 \%$ of $\Delta$ transpiration) whereas the much larger $\Delta$ transpiration $\left(15.7 \mu \mathrm{mol} \mathrm{s}^{-1}\right)$ of the following afternoon results in a $\Delta$ uptake $\left(2.6 \mu \mathrm{mol} \mathrm{s}^{-1}\right)$ which is only about $16 \%$ of the $\Delta$ transpiration. The water balance during the night of day $P$ (Fig. 4) did not change much, despite a markedly enhanced transpiration since uptake increased concomitant with transpiration. The small negative $J_{w}(n e t)$ after $24.00 \mathrm{~h}$ changed after $4 \mathrm{~h}$ into a positive one. Therefore, the plant's water reserve which had improved from day $\mathrm{S}$ at $18.00 \mathrm{~h}$ by about $65 \mathrm{mmol}$ (day P, $24.00 \mathrm{~h}$ ) decreased little. However, during the subsequent afternoon $J_{w}(n e t)$ became considerably negative as transpiration was increased drastically. The water balance dropped from $+124 \mathrm{mmol}$ at $12.30 \mathrm{~h}$ to $-36 \mathrm{mmol}$ at $03.00 \mathrm{~h}$ in the night of day $\mathrm{H}$ (Fig. 4). Therefore the plant used $160 \mathrm{mmol}$ or about $2.9 \mathrm{ml}$ of its water reserves to cover the excessive transpirational water loss in this time period. It is generally accepted that water reserves enable a succulent plant to survive long drought periods, but succulence can also buffer short time periods with a negative $J_{w}(n e t)$ as demonstrated here.

The heterogeneity in the responses of water uptake rates on substantially altered transpiration can originate from anatomical or physical limitations of the plant's hydraulics, mainly the conductivity of the xylem and the soil-root boundary or/and interferences by the CAM, as has been demonstrated for $S$. medley-woodii by Eller $e t$ al. (1988). Moreover, Eller and Ruess (1986) and Eller et al. (1988) showed that the water loss by transpiration of $S$. medley-woodii leaves varies characteristically with leaf age and, therefore, one can not assume that all leaves of a plant show the same reaction on changes of environmental conditions during the light and the dark periods, respectively. The increased uptake during the second part of the dark period of day $\mathrm{H}$ (Fig. 4) resulted from $\mathrm{CO}_{2}$ dark fixation. This is evident because, during the first part of that night, uptake started to decrease concomitant with the decrease of transpiration, but uptake had increased with the preceding night parallelling the accumulation of the osmotically active products of $\mathrm{CO}_{2}$ dark fixation. However, the marked increase of uptake after midnight of day $P$ is undoubtedly a consequence of increased transpiration as is the enhanced water uptake following the drastically increased transpiration in the afternoon of day $\mathrm{H}$ (Fig. 4). But why did uptake not increase during that afternoon to a value which would allow a value of $J_{w}$ (net) near zero as in the preceding night? During the whole time period presented in Fig. 5 uptake rates never exceeded $6 \mu \mathrm{mol} \mathrm{s}^{-1}$ irrespective of the maximal value of transpiration. One can assume that this value represented the upper limit for uptake caused by high resistances at the soil/root interface or in the root itself compared with resistances for water flow from internal water stores. Such an assumption is supported by equally limited uptake rates observed in the first $6 \mathrm{~d}$ not shown in Fig. 4. However, later on, the maximal uptake rates were higher which could be attributed to the observed root growth increasing the surface for water uptake.

The plant endured a substantial water loss during the hours of high temperature in the afternoon and the night of day $\mathrm{H}$ (Fig. 4). The plant's reaction was an increased uptake (minimum during the night of day $\mathrm{H}$ was $4.6 \mu \mathrm{mol} \mathrm{s}^{-1}$ compared with only $2.8 \mu \mathrm{mol} \mathrm{s}^{-1}$ on day S) to re-establish a positive $J_{w}(n e t)$ and a better plant water status. At the onset of the high temperatures $(24.00 \mathrm{~h}$, day P) the plant's water status had improved by a balance value of $+72.5 \mathrm{mmol}$ compared with its reserves at the beginning of the analysed period (Fig. 4, $18.00 \mathrm{~h}$ at day S, balance value set to zero). The balance dropped during the hot period to negative values, but high water uptakes 
1620 Flach et al.
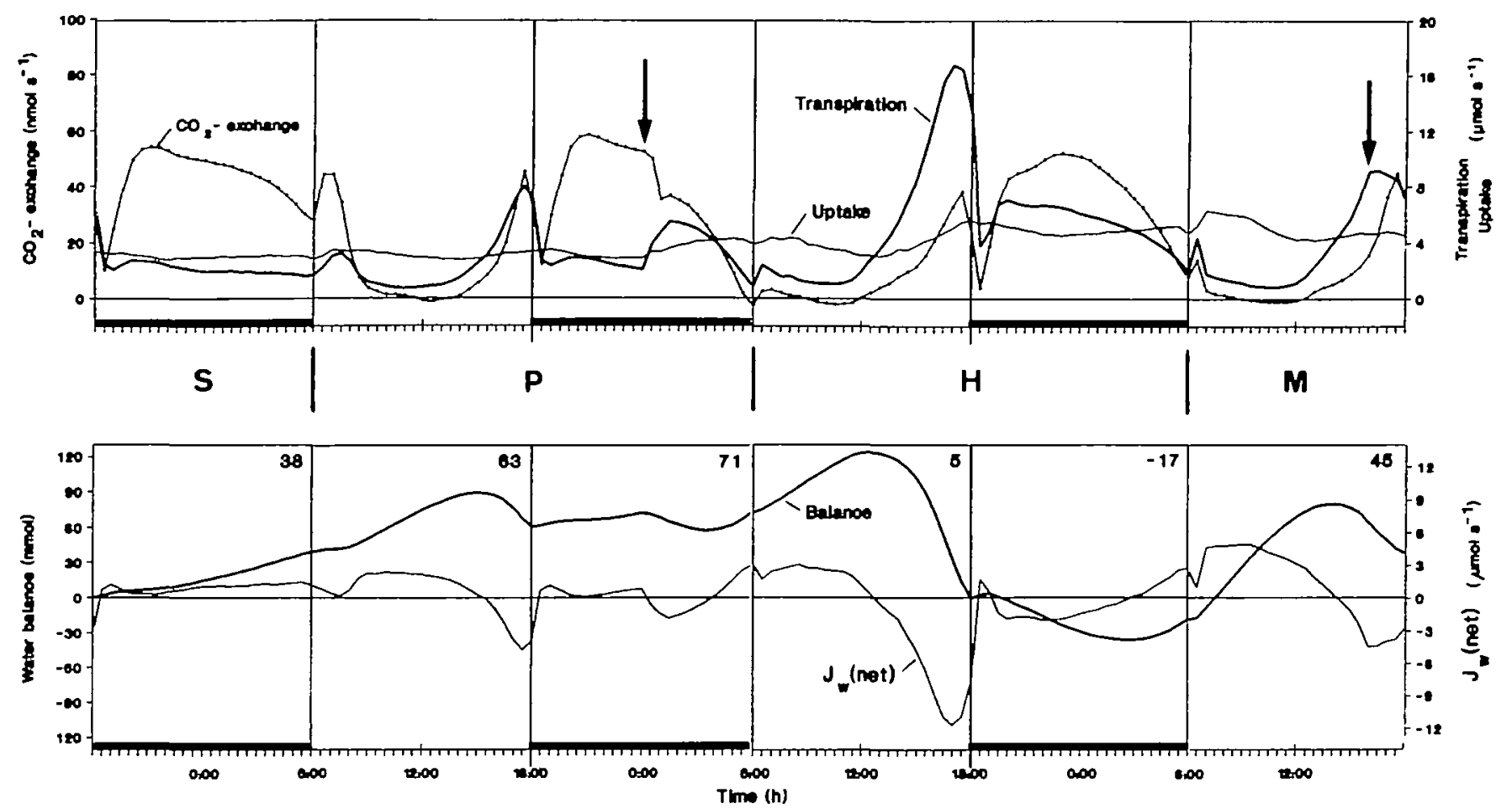

Fig. 4. Diurnal patterns of $\mathrm{CO}_{2}$ exchange and water relations of Senecio medley-woodii during a period with a hot day. S, P, $\mathrm{H}, \mathrm{M}$ : days with environmental conditions according to Fig. 1. 12/12 h light/dark period. Black bars indicate dark period. Figures in the upper right corner are the actual values of the water balance at the end of the preceding dark or light period. The time period covers days 7-10 of Fig. 6 . Arrows: start and end of the hot period.

throughout the night of day $\mathrm{H}$ and the whole of day $\mathrm{M}$ and, finally, the change to lower air temperatures (day $M$, $16.00 \mathrm{~h})$ re-established a positive water balance. At the end of the night of day $M$ (not shown in Fig. 4) the balance was restored at a level of $+74.5 \mathrm{mmol}$.

Figure 5 compares transpiration and uptake of the $S$. medley-woodii during the first $21 \mathrm{~d}$ of the experiment. Days $22-29$ with $30^{\circ} \mathrm{C}$ temperature both day and night are not shown since the values were similar to those of days 20 and 21. During the first hot day period (days 1-4) the transpiration in the light period (Fig. 5a) exceeded the uptake much more than during the following two periods (7-10, 13-15). However, the absolute values for transpiration on a per day basis (Fig. $5 \mathrm{~b}$ ) differed little. Absolute uptake rates (Fig. 5b) only varied to a small extent during the short hot day periods, but they increased markedly if the high air temperature conditions persisted for a longer period (after day 15). The plant improved its water balance after the stress of a short hot period within $2 \mathrm{~d}$ by reducing water loss through transpiration. Transpiration was markedly lowered predominantly during the light period of the first day (Fig. 5, day 5 or 11) after the stress period. The patterns resulting from this modulation of transpiration are surprisingly alike for the two hot day periods from days 3-8 and days 9-14, respectively. For the prolonged hot period (days 21-29) transpiration exceeded uptake only during the first day.
From the second day water uptake is already enhanced and transpiration reduced, mainly during the light period (Fig. 5).

Apart from the hot days the water uptake always exceeded transpiration. The water gain for the whole period of $29 \mathrm{~d}$ was $1390 \mathrm{mmol}$ or about $25 \mathrm{ml}$. During the precultivation the plant was well watered. It had very turgescent leaves and one can assume that its water stores were filled near or to its maximal storage volume. Thus one can conclude that this positive water balance was primarily used for the observed growth. For $S$. medleywoodii with a leaf water content of about $96 \%$ of fresh weight $(\mathrm{FW})$ and considering errors in the determination of leaf volumes one can assume that a water gain of $1 \mathrm{ml}$ provokes a leaf or plant volume increase of about the same magnitude. The young $S$. medley-woodii leaves were arranged in a dense rosette which unfortunately prevented determinations of changes in leaf volume, at least with an accuracy needed for a comparison with the observed mean daily positive water balance and to quantify the observed root growth would have been more or less a guess. A mature leaf of $S$. medley-woodii stores between 2-3 ml of water (Eller et al., 1988) and grows within 4-8 weeks to its full size. At the end of the $29 \mathrm{~d}$ experiment the plant had 34 leaves, 10 of them immature and still growing. The total FW was $63.2 \mathrm{~g}$ which represents $60 \mathrm{ml}$ water content. Thus, the measured water gain of about 

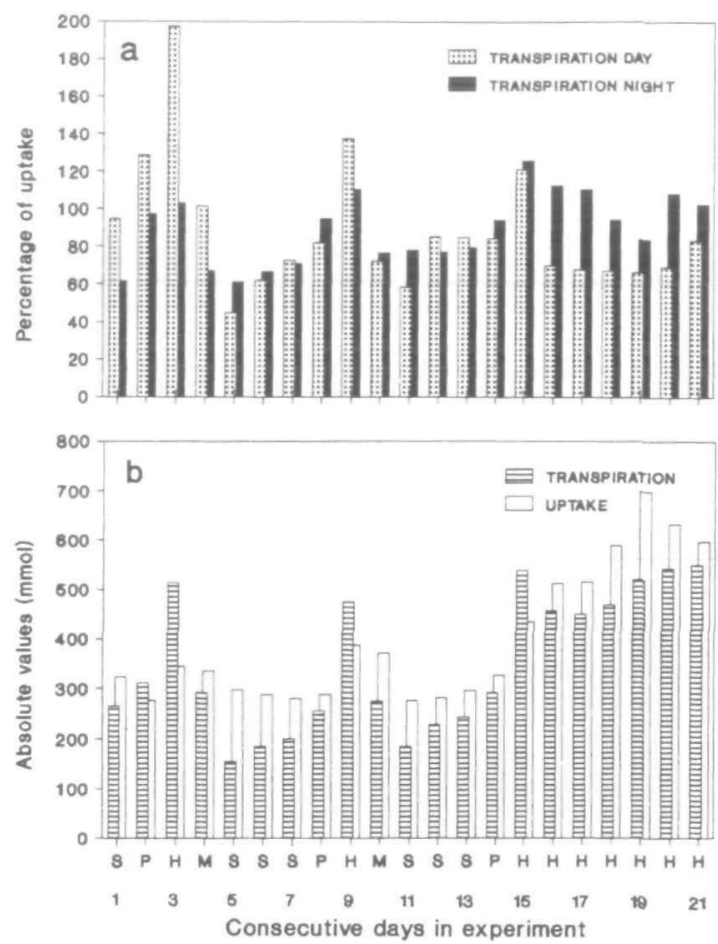

Fig. 5. Transpiration and water uptake of a Senecio medley-woodii plant measured in the water-budget-meter ( $F_{1 g}$. 3 ) during 21 consecutive days (days 1-21 of a period of $29 \mathrm{~d}$ ). S, P, H, M; days with environmental conditions according to Fig. I. Days $1-4,7-10,13-15$ are hot day periods (see Fig. 4 for details of period 7-10). (a) Transpiration as per cent of uptake (light period $06.00-18.00 \mathrm{~h}$, dark period 18.00-06.00 h). (b) Transpiration and uptake for $24 \mathrm{~h}$.

$0.86 \mathrm{ml} \mathrm{d}^{-1}$ represents a per day increase of $1.35 \%$ of the total leaf water not considering water used for root growth. If a leaf grows within 6 weeks to its full size with about $2.5 \mathrm{~g} \mathrm{FW}$ then the mean daily input of water into the mass of leaf water would be $0.057 \mathrm{ml}$ or for the 10 growing leaves $0.57 \mathrm{ml} \mathrm{d}^{-1}$. Considering root growth, the amount of water input into the plant's growth is of the same magnitude as the measured water gain of $0.86 \mathrm{ml}$.

The leaf mesophyll of Senecio medley-woodii plants is the water storing tissue which is more or less uniformly pigmented and venated and serves also as the plant's assimilatory tissue. However, some leaf succulents have tissues which show differentiation: a peripheral chlorenchyma which is generally not succulent takes care of photosynthesis while a weakly differentiated, but succulent, parenchyma stores water. Venation is situated at the boundary between the peripheral chlorenchyma and the central hydrenchyma. Plants with such partially succulent leaves (von Willert et al., 1992) could show a regulation of plant water status different from that of the all-cell succulent type like $S$. medley-woodii. Therefore, plants of Aloe jucunda with typical partially succulent leaves were also investigated. In Fig. 6 the daily uptake and transpiration values of the last 20 consecutive days of a $27 \mathrm{~d}$ experiment are represented. Some difficulties with the

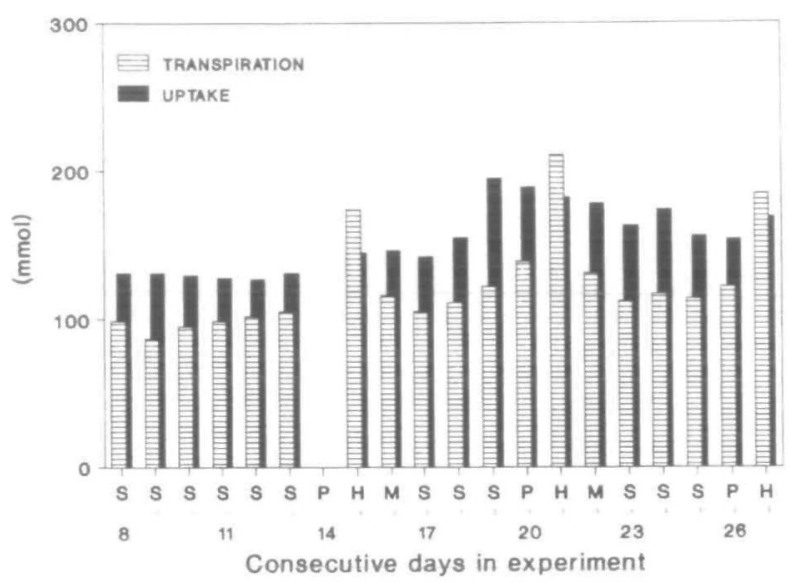

Fig. 6. Transpiration and water uptake ( $24 \mathrm{~h}$ periods) of Aloe jucunda during $20 \mathrm{~d}$ of consecutive measurements in the water-budget-meter (days 8-27 of a period of $27 \mathrm{~d}$ ). S, P, H, M: days with environmental conditions according to Fig. 1. Days 14-16, 20-22 and 26-27 are hot day periods. Black bar indicates dark period.

measuring system prevented accurate determinations during the first $7 \mathrm{~d}$ and on day 14 (Fig. 6). As for $S$. medley-woodii there were three transitions from standard day to hot day conditions. The plant was in an excellent physiological status with fully turgescent leaves

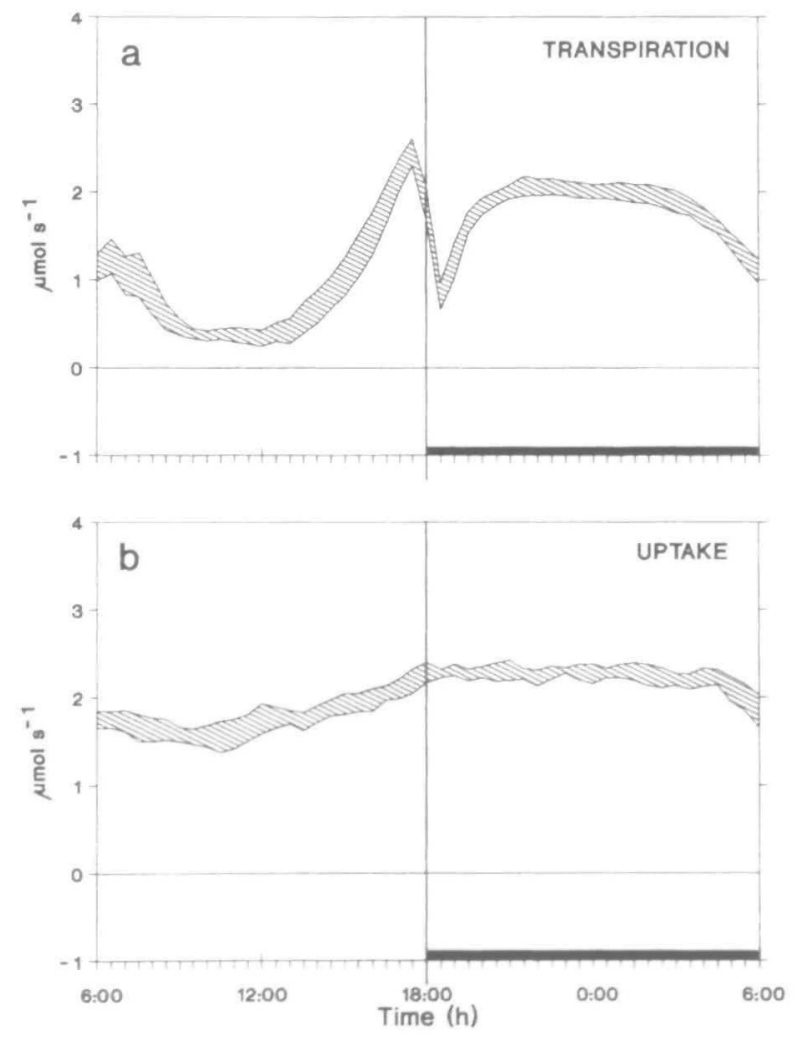

Fig. 7. Diumal pattern of transpiration and water uptake of Aloe jucunda during $7 \mathrm{~d}$ with environmental conditions of a standard day (Fig. 1, S). Curves standardized for equal $24 \mathrm{~h}$ sums (for details see text). The boundaries of the hatched areas envelop the standardized curves of days $2,3,4,10,11,17$, and 18 of a $27 \mathrm{~d}$ experiment. 

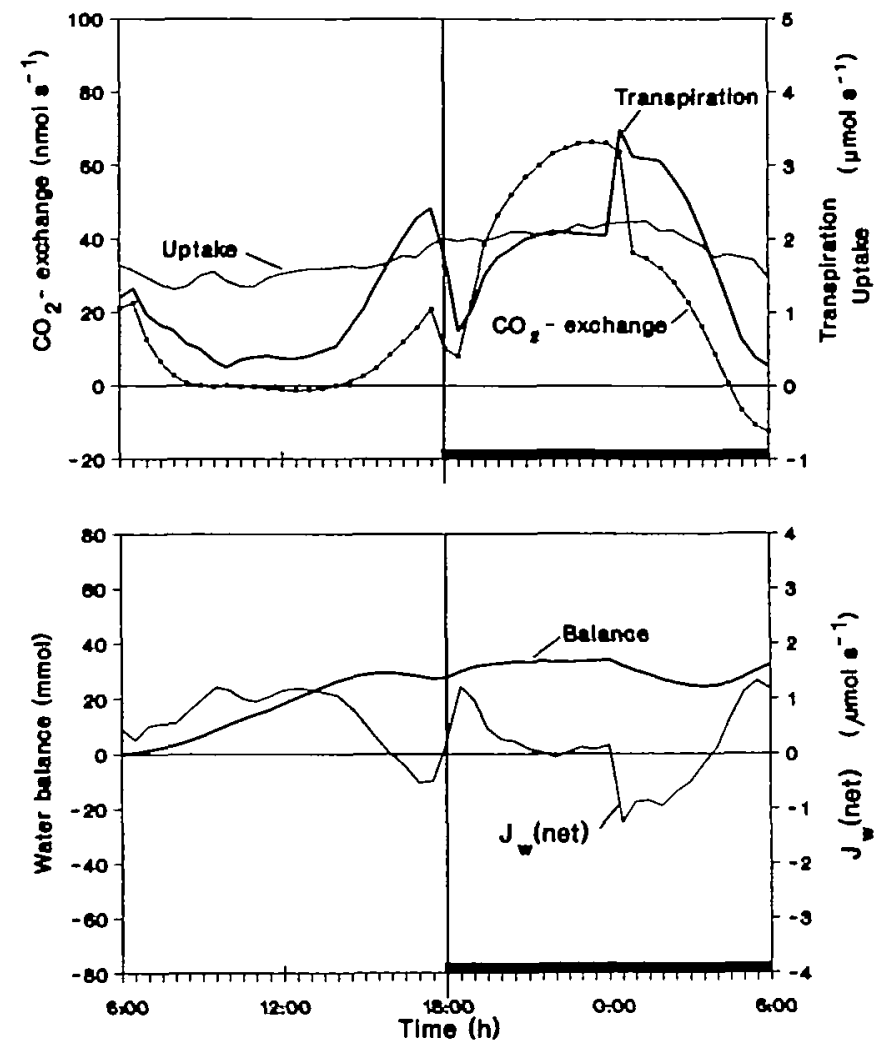

Fig. 8. Diumal pattern of $\mathrm{CO}_{2}$ exchange and water relations of an Aloe jucunda plant. Environmental conditions according to day $\mathrm{P}$ of Fig. 1 with onset of a hot day period at midnight. Black bar indicates dark period.

(water content $89 \%$ of $\mathrm{FW}$ ) and steadily growing over the whole measuring period. The mean surplus of water uptake during the six standard days (days 8-13, Fig. 6) was $32 \mathrm{mmol} \mathrm{d}^{-1}$ and the $24 \mathrm{~h}$-balance was, for the last three days (days 11-13, Fig. 6) of this time period, nearly constant. For the $20 \mathrm{~d}$ illustrated in Fig. 6 the surplus of water uptake was, on average, $33 \mathrm{mmol}$ or $0.59 \mathrm{ml} \mathrm{d}^{-1}$ which was evidently used for the observed leaf and root growth. This daily gain of water represents $1.2 \%$ of leaf FW (roots not considered).

In contrast to $S$. medley-woodii the response of the $A$. jucunda plant to the transitions from standard to hot day conditions (days 15, 21, 27, Fig. 6) was nearly identical for all three transitions. The plant's performance at standard day conditions was surprisingly stable concerning the diurnal pattern of transpiration and water uptake. To compare the curves at the beginning and at the end of the measuring period one has to take into account the increase of the absolute values due to growth. For comparison purposes transpiration and uptake rates were normalized to the day with the highest transpiration by multiplying with the quotient of the $24 \mathrm{~h}$ integrals of transpiration and uptake. In Fig. 7 the boundaries of the hatched areas envelop the seven standardized curves (days 2, 3, 4, 10, 11, 17, 18 of Fig. 6). Both areas are narrow and thus giving evidence that the diurnal courses of transpiration and uptake were very uniform with a distinct and characteristic diurnal rhythm. Moreover, the span between the boundaries is about the maximal error for such measurements as already outlined in Materials and methods. Figure 7 demonstrates that the plant's control of water flux results in a distinct diurnal pattern of transpiration and water uptake if water availability and environmental conditions do not vary.

The diurnal course of water uptake did not repeat the pattern of the transpiration curve in a direct way. The transpiration peaks or steep variations of transpiration, for example, at the transition from the light to the dark period (Fig. 7, $18.00 \mathrm{~h}$ ), were extremely smoothed by buffering from the water reserves stored in the hydrenchyma. This water store represents at midleaf about $45 \%$ of the leaf's cross-section. This buffering is also well demonstrated (Fig. 8) in a diurnal course of water relations with a transition from standard day to hot day conditions (Fig. 1, P). The drastically increased transpiration (after $24.00 \mathrm{~h}$ ) did not affect uptake rates. Therefore, the water budget became negative and the plant's water reserves decreased, as can be seen from the decrease of the water balance value. After the onset of the hot day conditions after midnight the impact on the balance 
values of $A$. jucunda with partially succulent leaves is very similar to that of $S$. medley-woodii (Fig. 4, P) with allcell succulence.

\section{Conclusions}

This investigation reports for the first time continuously recorded water uptake data of two succulent species under changing temperatures of the ambient air. The results demonstrated the efficacy of the improved WBM for the continuous determination of plant water relations during time periods of several weeks. The smallest significant uptake rate of $0.3 \mu \mathrm{mol} \mathrm{s}^{-1}$ is equal to $19.5 \mu \mathrm{h} \mathrm{h}^{-1}$ which is undoubtedly an excellent performance of a device designed to quantify transpiration and water uptake of a whole plant and to analyse control and correlation of the plant's water fluxes and to monitor changes in whole plant water status.

The two investigated species with different types of leaf succulence showed similar control of plant water relations and water fluxes. However, the observed daily courses of transpiration and uptake rates for $A$. jucunda, with its partially succulent leaves, were much less co-ordinated and buffered than for the all-cell succulent $S$. medleywoodii. Differences in short-term buffering of negative $J_{w}(n e t)$ were observed using the WBM.

The diurnal courses of transpiration and water uptake of $A$. jucunda varied, but normalized curves showed a characteristic pattern if the environmental conditions were identical (Fig. 7). Even intermediate short periods of heat stress (Figs 4, 8) with high transpiration had no impact on these diurnal patterns. The curves represent the plant's control according to the environmental conditions and the actual plant water status, but are also characterized by anatomical features and physiological parameters, for example, conductivities, water storage volumes etc. Information in the form of such normalized curves could be the starting point for modelling of plant water relations (Cowan, 1982; Thornley and Johnson, 1990) based on experimental evidence or could validate mathematical models (Weatherly, 1982; Smith et al., 1987) used to simulate water relations of succulents. However, more investigations with species of characteristically different types of leaf succulence are needed to reveal the impact of the anatomical details of hydrenchymas and the impact of the $\mathrm{CO}_{2}$ fixation mode on the diurnal changes of plant water relations. It is intended to improve the WBM with the aim of making feasible investigations of the substrate with a varying water potential, but there are still some major technical problems to solve.

\section{Acknowledgements}

The investigations were supported by a grant of the Swiss National Science Foundation (Grant 31-30895.91) and the
Stiftung für Wissenschaftliche Forschung an der Universităt Zürich.

\section{References}

Baker JM, Van Bavel CHM. 1987. Measurement of mass flow of water in the stems of herbaceous plants. Plant, Cell and Environment 10, 777-82.

Brunner U, Eller BM. 1975. Spontane Transpirationsänderungen unter konstanten Umgebungsbedingungen. Berichte der Schweizerischen Botanischen Gesellschaft 85, 289-97.

Cowan IR. 1982. Regulation of water use in relation to carbon gain in higher plants. In: Lange OL, Nobel PS, Osmond CB, Ziegler $\mathrm{H}$. eds. Physiological plant ecology, Vol. II. Encyclopedia of plant physiology, New series, Vol. 12B. Berlin: Springer-Verlag.

Eller BM, Ruess BR. 1986. Modulation of CAM and water balance of Senecio medley-woodii by environmental factors and age of leaf. Journal of Plant Physiology 125, 295-309.

Eller BM, Ruess BR, Sharma S. 1988. Carbon gain, water conservation and, expression of CAM during leaf development of Senecio medley-woodii. Journal of Plant Physiology 133, 304-9.

Eller BM, Ferrari S, Ruess BR. 1992. Spatial and diel variations of water relations in leaves of the CAM-plant Senecio medleywoodii. Botanica Helvetica 102, 193-200.

Eller BM, Egli A, Flach BM-T. 1993. Influence of transpiration and photosynthetic pathway on water uptake of Cotyledon orbiculata (CAM) and Othonna opima $\left(\mathrm{C}_{3}\right)$. Botanica Helvetica 103, 207-21.

Griffths H. 1988. Crassulacean acid metabolism: a re-appraisal of physiological plasticity in form and function. Advances in Botanical Research 15, 43-92.

Hilliard OM. 1977. Compositae in Natal. Pietermaritzburg: University of Natal Press.

Koch W, Klein E, Walz H. 1968. Neuartige Gaswechselmessanlage far Pflanzen in Laboratorium und Freiland. Siemens Zeitschrift 42, 392-404.

Lattge U. 1987. Carbon dioxide and water demand: crassulacean acid metabolism (CAM), a versatile ecological adaptation exemplifying the need for integration in ecophysiological work. The New Phytologist 106, 593-629.

Matyssek R, Tang A-C, Boyer JS. 1991. Plants can grow on internal water. Plant, Cell and Environment 14, 925-30.

Milne R. 1989. Diurnal water storage in the stem of Picea sitchensis (Bong.) Carr. Plant, Cell and Environment 12, 63-72.

Passioura JB. 1982. Water in the soil-plant-atmosphere continuum. In: Lange OL, Nobel PS, Osmond CB, Ziegler $\mathrm{H}$. eds. Physiological plant ecology, Vol. II, Encyclopedia of plant physiology, New series, Vol. 12B. Berlin: Springer-Verlag.

Reynolds GW. 1966. The Aloes of tropical Africa and Madagscar. Mbabane: The Aloes Book Fund.

Ruess BR, Eller BM. 1985. The correlation between crassulacean acid metabolism and water uptake in Senecio medley-woodii. Planta 166, 57-66.

Ruess BR, Eller BM, Ferrari S. 1988. Transpiration and water uptake of succulents in their natural habitat: field determinations with a potometer. Botanica Helvetica 98, 215-21.

Schulze ED, Cermak J, Matyssek R, Penka M, Zimmermann R, Vasicek F, Gries W, Kucera J. 1985. Canopy transpiration and water fluxes in the xylem of the trunk of Larix and Picea trees-a comparison of xylem flow, porometer and cuvette measurements. Oecologia 66, 475-83.

Smith JAC, Schulte PJ, Nobel PS. 1987. Water flow and water 
1624 Flach et al.

storage in Agave deserti: osmotic implications of crassulacean acid metabolism. Plant, Cell and Environment 10, 639-48.

Thomley JHM, Johnson IR. 1990. Plant and crop modelling. Oxford: Clarendon Press.

Weatherly PE. 1982. Water uptake and flow in roots. In: Lange OL, Nobel PS, Osmond CB, Ziegler H eds. Physiological plant ecology, Vol. II, Encyclopedia of plant physiology, New series, Vol. 12B. Berlin: Springer-Verlag.
Whitehead D, Jarvis PG. 1981. Coniferous forests and plantations. In: Kozlowski TT, ed. Water deficits and plant growth, Vol. VI. Woody plant communities. New York: Academic Press, 49-152.

Von Willert DJ, Eller BM, Werger MJA, Brinckmann E, Ihlenfeldt HD. 1992. Life strategies of succulents in deserts, with special reference to the Namib desert. Cambridge University Press. 